\title{
Organizaçōes sociais e instituiçōes governamentais: perspectivas de parceria na atenção à saúde da criança através dos voluntários e da pastoral da criança
}

\author{
SOCIAL ORGANIZATIONS AND GOVERNMENTAL INSTITUTIONS: PERSPECTIVES ON PARTNERSHIPS \\ IN CHILDREN'S HEALTH CARE THROUGH VOLUNTEERS AND THE PASTORAL DA CRIANÇA
}

ORGANIZACIONES SOCIALES E INSTITUCIONES GUBERNAMENTALES: PERSPECTIVAS DE TRABAJO EN CONJUNTO EN LAATENCIÓN A LA SALUD DEL NIÑO ATRAVÉS DE LOS VOLUNTARIOS Y DE LA PASTORAL DEL NIÑO

\section{Raquel Dully Andrade', Débora Falleiros de Mello²}

\section{RESUMO}

Este estudo objetiva apresentar algumas perspectivas de parceria entre organizações sociais e instituições governamentais na atenção à saúde da criança.Tratase de estudo reflexivo sobre participação social e as articulações entre serviços governamentais e não- governamentais na construção da consolidação do Sistema Único de Saúde, destacando o papel dos voluntários e dos profissionais de saúde nesse processo. Na assistência à infância, essas parcerias são potenciais, pela grande amplitude e destaque das organizações sociais dirigidas às crianças, particularmente a Pastoral da Criança, tornando importante o debate sobre políticas públicas que visem a estabelecer e a fortalecer esses vínculos no âmbito local e nacional.

\section{DESCRITORES}

Bem-estar da criança.

Organizações não-governamentais.

Trabalhadores voluntários.

\begin{abstract}
The aim of this research is to present perspectives on partnerships between social organizations and governmental institutions in children's health care. This study reflects on social participation and relations between governmental and nongovernmental services in constructing the consolidation of the Sistema Único de Saúde (Unified Health System), highlighting the role of volunteers and health professionals in this process. In child care, these associations are potential, due to the wide range and prominence of social organizations oriented towards children, particularly the Pastoral da Criança (the Catholic Church's Child Pastoral), which makes it important to discuss public policies aimed at establishing and strengthening these links in the local and national spheres.
\end{abstract}

\section{KEY WORDS}

Child welfare.

Non-governmental organizations. Voluntary workers.

\section{RESUMEN}

En este estudio se tuvo como objetivo presentar algunas perspectivas de trabajo conjunto entre organizaciones sociales e instituciones gubernamentales en la atención a la salud del niño. Se trata de un estudio reflexivo sobre participación social y las articulaciones entre servicios gubernamentales y no gubernamentales en la construcción de la consolidación del Sistema Único de Salud, destacando el papel de los voluntarios y de los profesionales de salud en ese proceso. En la asistencia a la infancia, esas asociaciones son potenciales, por la gran amplitud y destaque de las organizaciones sociales dirigidas a los niños, particularmente la Pastoral del Niño, tornando importante el debate sobre políticas públicas que visen establecer y fortalecer esos vínculos en el ámbito local y nacional.

\section{DESCRIPTORES}

Bienestar del niño.

Organizaciones no

gubernamentales.

Trabajadores voluntarios.
1 MestrandaEnfermagem em Saúde PúblicaEscola de Enfermagem de Ribeirão Preto-Universidade de São Paulo (EERP-USP)

2 Professora Doutora do Departamento de Enfermagem Materno Infantil e Saúde Pública da EERP-USP

dully@passosuemg.br 


\section{INTRODUÇÃO}

Em relação à atual situação de saúde da criança, pode-se observar que o Brasil apresenta um quadro de avanços importantes, mas com grandes desafios a enfrentar. Uma das conquistas do país, nas últimas décadas, foi a queda no índice de mortalidade infantil, que em 1990 era de 49,4 por mil nascidos vivos e em 2001 foi de 34,6, entretanto o coeficiente se mantém alto quando comparado com outros países que têm taxas mais baixas, como Venezuela, Panamá e Cuba, com índices respectivos de 21, 18 e 7 por mil nascidos vivos. Além disso, continua alta a morbimortalidade por doenças preveníveis $^{(1)}$.

Entre os desafios dessa realidade está o de criar alternativas para combater as consequiências da grave desigualdade social. Em levantamento de $2001^{(1)}$, foi constatado que $30,5 \%$ das famílias brasileiras com crianças entre 0 e 6 anos de idade vivem com renda per capita igual ou inferior a meio salário mínimo.

Limitações do Estado para intervir nessa realidade vêm sendo apontadas, e é relevante salientar que a criança tende a ser especialmente vulnerável a todas as dificuldades a serem enfrentadas por suas famílias, principalmente em seus primeiros anos de vida, tornando-se importante ressaltar que a Constituição Federal de 1988 prevê a prioridade absoluta a crianças e adolescentes como dever da família, da sociedade e do Estado. Diante disso é importante buscar compreender o papel de cada uma dessas esferas na promoção da saúde infantil, considerando as relações entre elas, com suas limitações e potencialidades.

mediante políticas sociais compensatórias e focalizadas, num contexto neoliberal e em acordo com os programas de ajuste estrutural preconizados para os países latino-americanos pelo Banco Mundial, buscando a contenção de gastos públicos, a privatização e a desregulamentação do Estado. No início da década de 90, essa situação passa a receber inúmeras críticas, em um cenário onde as desigualdades sociais cada vez mais se ampliam e se aprofundam, tornando problemática a seletividade na direção da proteção social apenas para os mais excluídos dos benefícios econômicos e sociais ${ }^{(2)}$.

Nesse contexto, destaca-se a carta constitucional de 1988, apresentando significativos avanços no sistema de proteção social, trazendo a universalidade do direito aos benefícios a todos os cidadãos (contribuintes ou não), a proposta de equidade no acesso e na forma de participação no custeio, a uniformidade e equivalência dos benefícios e serviços, a diversidade de sua base de financiamento e a gestão administrativa descentralizada, com maior possibilidade de participação da comunidade. Dessa forma, o conceito de seguridade social vem em lugar do de seguro social, através de um conjunto de leis assegurando os direitos relativos à A baixa participação saúde, assistência e previdência social ${ }^{(3)}$.

política e a maneira como foram distribuídos, historicamente, os benefícios sociais brasileiros, impossibilitam que sejam considerados conquistas democráticas...
Diante desse cenário, torna-se importante refletir sobre os papéis do Estado e da sociedade no enfrentamento dos problemas sociais da população, de forma que haja o reconhecimento da importância de Organizações Não Governamentais (ONG), organizações sociais e comunitárias nesse processo, mas que este não seja compreendido e utilizado como estratégia voltada ao desvio de responsabilidade estatal e nem à manutenção do tradicional assistencialismo, mas como alternativa para criação e ampliação dos laços e redes de solidariedade e de fortalecimento da cidadania.

Assim, num momento em que os movimentos sociais ganham espaço, atenta-se para a possibilidade de parcerias intersetoriais e interinstitucionais, com conseqüente construção conjunta de iniciativas para a solução de problemas públicos, evitando a negação ao Estado e a fragmentação das ações ${ }^{(2)}$.

A baixa participação política e a maneira como foram distribuídos, historicamente, os benefícios sociais brasileiros, impossibilitam que sejam considerados conquistas democráticas e compromete a contribuição para o desenvolvimento da cidadania ativa. Essa herança pode ser um dos principais aspectos relacionados ao fato de os vínculos associativos, a despeito dos recentes avanços, ainda tenderem a ser precários, frouxos e pouco eficazes na consolidação da organização de interesses e da ação coletiva, como elementos centrais de uma busca conjunta da superação dos problemas sociais ${ }^{(2)}$.

Em relação à responsabilidade sobre as questões sociais por parte do Estado, nos anos 80 essa era prevista apenas

\section{AS POSSIBILIDADES DE PARTICIPAÇÃO SOCIAL}

Organizações sociais e instituições governamentais: perspectivas de parceria na atenção à saúde da criança ... Andrade RD, Mello DF. 
Entretanto, relações mais participativas e o reconhecimento do potencial de parcerias entre as organizações sociais e as governamentais vêm sendo facilitados à luz da maior importância que se tem dado à participação social na área da saúde, principalmente depois da reforma nesse setor, que culminou com o Sistema Único de Saúde (SUS) em 1990, que tem como parte de seus princípios a participação comunitária e o controle social. Organizações externas à instituição governamental têm maiores possibilidades de contribuir para a consolidação de técnicas de trabalho que refletem um enfoque integrado e que incluem métodos de participação dirigidos a fortalecer o processo de reforma no setor saúde, o que é favorecido pelo seu permanente contato com a sociedade civil e seus diversos atores sociais ${ }^{(4)}$.

Aqui a figura da ONG vem se destacando, tornando cada vez mais presente nas propostas do setor saúde. Essa tendência foi claramente enfatizada no ano de 1996, tanto pela Organização das Nações Unidas (ONU), como pela Organização Panamericana de Saúde (OPAS), propondo mecanismos de diálogo entre governos e ONGs no planejamento, execução e avaliação das atividades derivadas das prioridades nacionais de saúde. Nesse sentido, torna-se importante estabelecer objetivos operacionais específicos, como coordenar os serviços prestados nessas duas esferas com o intuito de evitar duplicações de serviços prestados e desperdícios de recursos, assim como oferecer capacitação técnica e desenvolvimento de planos de ação nacionais em direção a essa mútua colaboração, inclusive mediante a tradução em grande escala de experiências que se mostraram exitosas em pequena escala ${ }^{(4)}$.

Não se pode negligenciar que existem aspectos limitadores a serem trabalhados, entre os quais são apontadas: a tradição de um ambiente social e político muito centralizado, a concepção de que o governo é a única esfera legítima de atenção, a pouca disposição em estabelecer diálogos entre as instâncias governamentais e não governamentais por parte de ambas, assim como a pouca coordenação entre essas, além da comum percepção de que as organizações sociais não são tão efetivas e eficientes, possuindo capacidade técnica e administrativa incipientes ${ }^{(4)}$.

Diante da relevância do estabelecimento de parcerias, considerando que esse processo apresenta dificuldades e potencialidades, compreende-se ser importante o estudo dessas relações, já que o desenvolvimento de práticas articuladas, sistematicamente, entre organizações sociais e governamentais, tanto na esfera local como nacional, representa um caminho que pode trazer bons resultados no avanço da construção de um sistema de saúde mais integrado e participativo, fortalecendo seus resultados, entrelaçando as ações dos profissionais de saúde e de todos os atores sociais envolvidos no processo de amadurecimento da cidadania.

\section{O VOLUNTARIADO}

Na busca de uma libertação da aqui já comentada herança autoritária, em que os direitos sociais foram instituídos neste país, os voluntários podem representar atores sociais importantes na trajetória de construção de uma maior participação da sociedade, no enfrentamento das adversidades sociais presentes na realidade da população brasileira.

$\mathrm{Na}$ ação voluntária costumam estar presentes o desejo de fazer mudanças e a disposição para implementar práticas concretas e eficientes, exercitando a cidadania num dos seus mais significativos aspectos, que é o da responsabilidade diante da realidade social e do compromisso em tentar transformá-la ${ }^{(2)}$.

Mesmo diante destas potencialidades, há que se atentar para as limitações desses atores sociais, já que os problemas a serem enfrentados são representados por diferentes privações, configurando muitas vezes soluções que não são passíveis de serem contempladas sem a intervenção do Estado e de múltiplas parcerias.

Outro aspecto a ser considerado na busca de uma compreensão mais ampla e menos ingênua, é a autonomia e a liberdade desses agentes sociais, que podem ser expressas na delimitação dos grupos atendidos, o que nem sempre ocorre no sentido de garantir maior equidade, mas pode acontecer, por exemplo, baseado em convicções religiosas ou político-partidárias.

Em relação à possibilidade de vínculo entre voluntários e profissionais de saúde, por um lado as propostas de treinamento de voluntários para serviços básicos de saúde ocorrem na maioria das vezes privilegiando pessoal de nível escolar elementar e médio, selecionado na própria comunidade onde irá atuar, podendo conter elementos de uma desprofissionalização desses serviços, por outro lado podem representar uma tendência de transferir saber para não profissionais envolvidos com suas comunidades e de considerar a própria população como sendo um importante recurso humano para as ações de saúde, representando uma mudança política na estrutura dos serviços de saúde, na medida em que poderia contribuir para uma repartição do saber e do poder ${ }^{(5)}$.

Diante dessa potencialidade, torna-se importante refletir sobre as reais possibilidades da transmissão de conhecimentos e de sua utilização pela população, bem como sobre os limites e dificuldades de modificação na estrutura de poder dos serviços de saúde.

Assim, um aspecto importante a assinalar é a forma pela qual os voluntários são considerados pela equipe de saúde e pela população. $\mathrm{O}$ estudo acima ${ }^{(5)}$, mostrou que no primeiro caso, o voluntário, muitas vezes, não tem toda sua potencialidade explorada pela equipe, tendendo a representar uma espécie de auxiliar. Já em relação à visão da população, especialmente numa zona urbana onde os recursos médicos são abundantes, seu papel poderá facilmente res- 
tringir-se ao de um atendimento acessório, de segunda categoria e menos prestigiado que os serviços institucionais.

Mesmo considerando a existência de fatores limitantes e que devem ser trabalhados, ressalta-se que as possibilidades de se incluir o voluntariado como participante ativo nas propostas para o setor saúde são promissoras. Em estudo realizado em nove países latino-americanos, demonstrou-se que há uma grande variação no alcance e tipos de atividades realizadas pelos voluntários, que dependem menos de habilidades individuais, condições locais ou disponibilidade de verbas, e mais dos preconceitos e parcialidade dos planejadores, instrutores e coordenadores de projetos, de forma que muitas vezes o voluntário recebe informações de maneira fragmentada, sendo orientado e influenciado para seguir uma lista de normas, que acabam por afastar-se de um projeto civilizatório e participativo, tornando-se um meio de conseguir auxilio à equipe e controle da comunidade ${ }^{(5)}$.

Nesse processo, articulado a profissionais conscientemente comprometidos na construção de políticas públicas viáveis, que visem qualidade de vida e participação social, o voluntário pode representar um recurso humano essencial, devendo integrar-se a um processo de trabalho que vise essencialmente acabar com disparidades opressivas.

Atualmente está em ascendência a idéia de valorizar o papel do voluntário para o desenvolvimento social do globo. Em acordo com essa tendência, o ano de 2001 foi declarado Ano Internacional do Voluntário pela Organização das Nações Unidas, através de uma assembléia realizada em 1997, contando com o apoio de 123 países, entre eles o Brasil ${ }^{(6)}$.

Dentro desse contexto, ainda segundo esta referência ${ }^{(6)}$, no Brasil busca-se reconhecer o trabalho do voluntário através do desenvolvimento de ações como treinamento, formação de multiplicadores e oferecimento de suporte institucional, além do incentivo a pesquisas sobre o assunto. Aqui se destaca o atendimento a população infantil, visto que de acordo com a mesma fonte, na distribuição de entidades voluntárias por áreas de atuação no Brasil, em primeiro lugar está a assistência a crianças e entre as 40 maiores equipes de voluntários, a Pastoral da Criança do Paraná ocupa a primeira posição.

Essa vantagem representa um fator favorecedor importante, para que se tornem promissoras as políticas públicas de atenção à saúde da criança, com vistas à articulação com ações de organizações sociais, enfatizando aqui a figura da Pastoral da Criança, a qual vem se destacando no campo de assistência à população infantil, suas famílias e comunidades.

\section{A PASTORAL DA CRIANÇA}

A Pastoral da Criança (PC) foi criada em 1983, é um Organismo de Ação Social da Conferência Nacional dos Bispos do Brasil-CNBB, sem fins lucrativos, de natureza filantrópica, decretada de Utilidade Pública Federal e que tem como base de todo o seu trabalho a comunidade e a família voltadas para a sobrevivência infantil, seu desenvolvimento integral e a solidariedade entre famílias ${ }^{(7)}$.

A dinâmica dessa organização consiste em treinar voluntários, denominados líderes comunitários, em sua maioria mulheres, para a mobilização das famílias em atividades como a vigilância nutricional, através da pesagem mensal das crianças, do acompanhamento do seu desenvolvimento e de outros cuidados básicos, tais como aleitamento materno, reidratação oral, imunizações, controle de infecções respiratórias, desenvolvimento de alimentos enriquecidos, plantas medicinais e acompanhamento da gestante. Recentemente, outras ações vêm sendo desenvolvidas na busca não só da sobrevivência infantil, mas também do desenvolvimento integral e melhoria da qualidade de vida das crianças atendidas. Aqui se destacam projetos como a Saúde Mental Comunitária, que concentra esforços em diminuir as tensões pessoais, familiares e comunitárias, além de outros que objetivam oferecer suporte material e capacitação às famílias e comunidades, como os projetos de geração de renda, alfabetização de jovens e adultos, participação no controle social e comunicação social ${ }^{(8)}$

Em relação às características das crianças e famílias que participam dessa organização social, observa-se a prevalência das crianças negras e daquelas com dois ou mais irmãos mais velhos, sendo que entre os fatores familiares estão a idade materna acima dos 25 anos, o fato de a mãe não trabalhar fora de casa, renda per capita baixa, menor escolaridade dos pais, tempo de moradia no bairro assistido superior a quatro anos e morte de filho menor de cinco anos. Já entre os motivos alegados para o abandono do acompanhamento, estão a migração, a falta de tempo e a interrupção das atividades pela Pastoral ${ }^{(9)}$. Observa-se que a PC tende a agregar as famílias e crianças que apresentam maior risco social, podendo contribuir com os serviços de saúde para um atendimento mais eqüitativo, de forma que essa parceria poderia fortalecer as ações e sustentabilidade da Pastoral, reduzindo a taxa de abandono.

Estudos têm mostrado aspectos positivos e lacunas na atuação da PC, mostrando áreas em que maiores investimentos são necessários. Assim, as orientações fornecidas pelos voluntários dessa associação comunitária vêm sendo relacionadas ao melhor conhecimento das mães atendidas sobre cuidados com a saúde da criança, embora venham sendo detectadas áreas da educação em saúde que estejam apresentando falhas, já que muitas das instruções incluídas no Manual de Treinamento da Pastoral não estão sendo aplicadas adequadamente, demonstrando a necessidade de reformulação do treinamento ministrado aos líderes comunitários $^{(10-11)}$. Aqui, considera-se que os profissionais 
dos serviços públicos de saúde voltados à comunidade poderiam se tornar aliados na capacitação desses voluntários de saúde.

Diante disso, mostra-se desejável a soma de esforços de vários segmentos sociais e públicos, na busca de garantir melhoria na qualidade de vida das crianças. Nessa perspectiva, cientes da dimensão ampla e complexa do seu objeto de trabalho, os atores sociais envolvidos no planejamento e gerenciamento da Pastoral da Criança, já vêm propondo como estratégia de trabalho, o estabelecimento de parcerias com governantes e dirigentes, buscando a mobilização e concentração de esforços, a complemen-tariedade de ações, a racionalização de recursos financeiros e humanos, compartilhando responsabilidades em prol de um objetivo comum $^{(7)}$.

Nessa perspectiva, torna-se imprescindível que ações intersetoriais sejam incorporadas às práticas das unidades de saúde, com vistas a estabelecer relacionamentos profissionais com as associações comunitárias ${ }^{(12)}$.

Considera-se que uma maior interação entre essa instituição social e os serviços públicos que prestam assistência primária à criança, pode potencializar os impactos das ações em prol desse grupo etário, possibilitando, ainda, um processo mais participativo nas práticas de saúde e promovendo uma maior autonomia comunitária. Entretanto, compreende-se que o desenvolvimento real dessa idéia pressupõe um envolvimento efetivo dos atores sociais envolvidos, destacando-se aqui a figura do voluntário e do profissional de saúde, tornando-se importante estudar a participação e o papel destes na operacionalização dessa proposta articuladora.

\section{REFERÊNCIAS}

(1) Fundo das Nações Unidas para a Infância (UNICEF). Situação da infância brasileira 2001.[online] Disponível em: www.unicef.org.br. (Acesso em 09 jul. 2001).

(2) Magalhães R. Enfrentando a pobreza, reconstruindo vínculos sociais: as lições da Ação da Cidadania contra a Fome, a Miséria e pela Vida. Cad Saúde Pública. 2002;18(supl):121-37.

(3) Cohn A. A saúde na previdência social e na seguridade social: antigos estigmas e novos desafios. In: Cohn A, Elias PE. Saúde no Brasil: políticas e organizações de saúde. São Paulo: Cortez; 1996. cap. 1, p. 11-55.

(4) Dickson K. Colaboracion entre organizaciones no gubernamentales y los gobiernos en la reforma del sector de la salud. Rev Panam Salud-Publica. 1997;1(4):324-9.

(5) Scaravaglione D, Coroilli EM, Witt RR, Renieri T. Voluntários de saúde: mito ou realidade. Rev Bras de Enferm. 1984;37(34):262-9.

(6) Ano Internacional do Voluntariado: 2001. [online] Disponível em < www.voluntarios.com.br>. (Acesso em 02 maio 2001).

\section{CONSIDERAÇÕES FINAIS}

No atual sistema de saúde brasileiro e com os desafios presentes no campo de assistência à criança, conformados em uma realidade com sérias discrepâncias sociais, percebese um momento em que organizações sociais e comunitárias vêm se fortalecendo. Nesse quadro ganham relevância a amplitude e os resultados das organizações sociais de atenção ao grupo etário infantil, salientando aqui o importante espaço ocupado pela Pastoral da Criança, a qual vem se destacando por meio da organização e dos resultados de seu trabalho.

Assim, despontam os possíveis resultados de uma articulação efetiva entre essas organizações sociais e as instituições governamentais de saúde quanto aos indicadores de qualidade e de impacto na área da saúde da criança, sendo relevante uma reflexão sobre as relações entre essas esferas de assistência, incluindo aqui um olhar sobre potencialidades e limitações e sobre a importância da participação dos profissionais de saúde nessa dinâmica.

É de extrema importância aprofundar a discussão sobre o desenvolvimento de políticas públicas efetivas direcionadas ao estabelecimento e fortalecimento desses vínculos na atenção à saúde infantil, com vistas à otimização da atuação dos serviços de assistência a essa população, tanto os governamentais quanto os não governamentais, trazendo novos questionamentos sobre as chances de maior impacto nos indicadores de saúde dessa faixa etária, abrindo o debate sobre uma maior participação e controle social na área da saúde, visando a consolidação do SUS.

(7) Pastoral da Criança. [online] Disponível em: <www. rebidia. org.br>. (Acesso em 03 ago. 2003).

(8) Pastoral da Criança. Guia do líder da Pastoral da Criança. $3^{a}$ ed. Curitiba: [s.n.]; 2000.

(9) Neumann NA, Victora CG, Halpern R, Guimarães PRV, César JA. A Pastoral da Criança em Criciúma, Santa Catarina, Brasil: cobertura e características sócio-demográficas das famílias participantes. Cad Saúde Pública. 1999;15(3):543-52.

(10) Neumann NA, Victora CG, Halpern R, Guimarães PRV, César JA. Desempenho da Pastoral da Criança na promoção de ações de sobrevivência infantil e na educação em saúde em Criciúma, uma cidade do sul do Brasil. Rev Panam Salud Publica. 1999;5(6):400-10.

(11) Barros FC, Victora CG. Avaliação do manejo da diarréia em menores de cinco anos no Nordeste do Brasil. J Pediatr. 1989;65(11/12):420-64.

(12) Fracolli LA, Zoboli ELCP. Descrição e análise do acolhimento: uma contribuição para o Programa de Saúde da Família. Rev Esc Enferm USP. 2004;38(2):143-51. 